\title{
Characterization of the Substances \\ Causing Deformation of Root Hairs of Trifolium repens when Inoculated with Rhizobium trifolii
}

\author{
By B. SOLHEIM AND J. RAA* \\ Institute for General Microbiology, University of Bergen, \\ $N-5000$ Bergen, Norway
}

(Received I4 January I972; revised I9 March I973)

\begin{abstract}
SUMMARY
Culture filtrate of Rhizobium trifolii and root media of Trifolium repens inoculated with this bacterium contain at least two factors able to cause deformation of root hairs of $T$. repens. One has properties of a nucleic acid, the other of either protein or polysaccharide. The deforming substances in culture filtrate are heat-labile whereas those in inoculated root medium are stable.

A heat-stable, root hair-deforming component is formed when culture filtrate is mixed with non-inoculated root medium. The deforming substances in the culture filtrate can be adsorbed to clover roots, and eluted with dilute acetic acid or urea. The role of the substances in the binding of rhizobia to clover roots and in the infection process is discussed.
\end{abstract}

\section{INTRODUCTION}

The first visible sign of interaction between legumes and Rhizobium is a characteristic deformation of root hairs. This deformation may include branching and various degrees of curling. Deformation of root hairs occurs before infection thread formation. Only exceptionally is an infection thread formed without apparent deformation of the root hair. This suggests that the deformation is essential for infection to occur. Root-hair deformation is not always followed by infection-thread formation, and also some non-infective strains of Rhizobium may cause deformation (Sahlman \& Fåhraeus, 1963; Li \& Hubbell, I969; Yao \& Vincent, 1969). Thus deformation of root hairs and formation of the infection thread are two separate steps in the infection process.

We (Solheim \& Raa, I97I) have presented evidence against the earlier theory of specific induction of pectinase as the basis for specificity in Rhizobium/legume associations.

The material in exudates of rhizobia grown in vitro which deforms root hairs is non-dialysable and loses its deforming ability when heated to $80^{\circ} \mathrm{C}$ for $20 \mathrm{~min}$ (Ljunggren, I969). However, root media of hosts inoculated with infecting homologous strains of Rhizobium apparently contain deforming factors stable at $80^{\circ} \mathrm{C}$ (Yao \& Vincent, I969) or II ${ }^{\circ} \mathrm{C}$ (Ljunggren, 1969) for $20 \mathrm{~min}$. Gel filtration on Sephadex G 25 and G 50 indicates a mol. wt of around 5000 of one deforming factor in inoculated root medium (Ljunggren, 1969). This paper further characterizes the deforming substances and discusses their possible role in infection.

\footnotetext{
* Present address: University of Tromsø, N-9000 Tromsø, Norway.
} 


\section{METHODS}

Culture methods. Trifolium repens L. cv. BETA (Swedish Seed Association, Svalöv) was used as host plant and Rhizobium trifolii strain U226 as inoculum. This strain was kindly supplied from the culture collection at the Department of Microbiology, Agricultural College of Sweden, Uppsala.

Rhizobium trifolii was grown in shake culture at $28^{\circ} \mathrm{C}$ on a defined medium (Graham, 1963) containing only dialysable components. After 5 days the bacteria were removed by centrifugation and the supernatant (culture filtrate) fractionated on a column of methylated albumin-kieselguhr (MAK) before being bioassayed for root-hair deforming substances. Both this culture filtrate of the bacterium grown in vitro, and the root medium of Trifolium repens inoculated with $R$. trifolii were bioassayed. This inoculated root medium was obtained as follows. Dry seeds were surface-sterilized with concentrated sulphuric acid for $20 \mathrm{~min}$ and then washed eight times in sterile distilled water over a period of $6 \mathrm{~h}$. The seeds were germinated in sterile $10 \mathrm{~cm}$ Petri dishes (250 seeds in $3 \mathrm{ml} \mathrm{H}_{2} \mathrm{O} /$ dish) in the dark for 2 days before inoculation with $2 \mathrm{ml} R$. trifolii $\left(\mathrm{IO}^{8}\right.$ to $10^{9}$ organisms $/ \mathrm{ml}$ ) obtained by suspending bacteria from solid agar medium in sterile distilled water (Ljunggren, 1969). Then seed dishes were kept in the light for 2 days. The root media from 40 such dishes were united and filtered through cotton, centrifuged to remove bacteria, dialysed against distilled water at $4^{\circ} \mathrm{C}$ for $48 \mathrm{~h}$, and finally concentrated by evaporation at reduced pressure at $28^{\circ} \mathrm{C}$ to a volume corresponding to $\mathrm{I} \mathrm{ml} / \mathrm{dish}$. This concentrated root medium was fractionated before being bioassayed.

Heat treatment. The effect of exudates from non-inoculated Trifolium repens plants on the heat stability of the deforming substances in culture filtrate of Rhizobium trifolii was examined. Culture filtrate of bacteria grown in vitro, and concentrated root media from noninoculated clover plants were obtained as described above. Equal volumes of culture filtrate and of concentrated root medium were mixed, and then heated in a water bath for 20 min at $85^{\circ} \mathrm{C}$. Concentrated root medium of clover plants inoculated with $R$. trifolii, and culture filtrate of the bacterium were also heated. All fractions were bioassayed after sterile filtration on $0.22 \mu \mathrm{m}$ Millipore filter.

Fractionation on a column of methylated albumin adsorbed to kieselguhr (MAK). Methylated albumin was synthesized and adsorbed to kieselguhr (Mandell \& Hershey, 1960). The column was eluted stepwise with $100 \mathrm{ml} 0.4 \mathrm{~N}, 0.6 \mathrm{~N}, 0.8 \mathrm{~N}$ and finally $100 \mathrm{ml} \mathrm{I} \cdot 2 \mathrm{~N}-\mathrm{NaCl}$ in $0.05 \mathrm{M}$-potassium phosphate, $\mathrm{pH} \mathrm{6.7.} \mathrm{The} \mathrm{four} \mathrm{fractions} \mathrm{thus} \mathrm{obtained} \mathrm{were} \mathrm{dialysed} \mathrm{and}$ each fraction concentrated to the same volume as that put on the column by evaporation at reduced pressure at $28^{\circ} \mathrm{C}$. The fractions were sterile filtered on Millipore filter, type GS pore size $0.22 \mu \mathrm{m}$ before bioassaying. To avoid plugging of the column by polysaccharides the MAK was suspended in the culture filtrate before being packed in a column.

Fractionation on Ca-apatite. Ca-apatite (Levin, 1962) was suspended in the concentrated root medium, stirred for $5 \mathrm{~min}$ and then removed by centrifugation and the supernatant, containing non-adsorbing substances, collected as fraction $\mathrm{I}$. The Ca-apatite was then eluted with $0.3 \mathrm{M}$ (fraction 2) and $\mathrm{I} \cdot 0 \mathrm{M}$ (fraction 3) potassium phosphate, $\mathrm{pH} 5.8$, and finally with saturated potassium pyrophosphate (fraction 4). Between each elution step the Ca-apatite was washed three times by suspension in the elution medium and centrifugation, the supernatants being discarded. The fractions were dialysed, concentrated and sterilefiltered as before.

Bioassay. Sterilized seeds were germinated in the dark for 2 days in inverted Petri dishes containing I \% agar in water. These plants were transferred to Fåhraeus (I957) slides as 

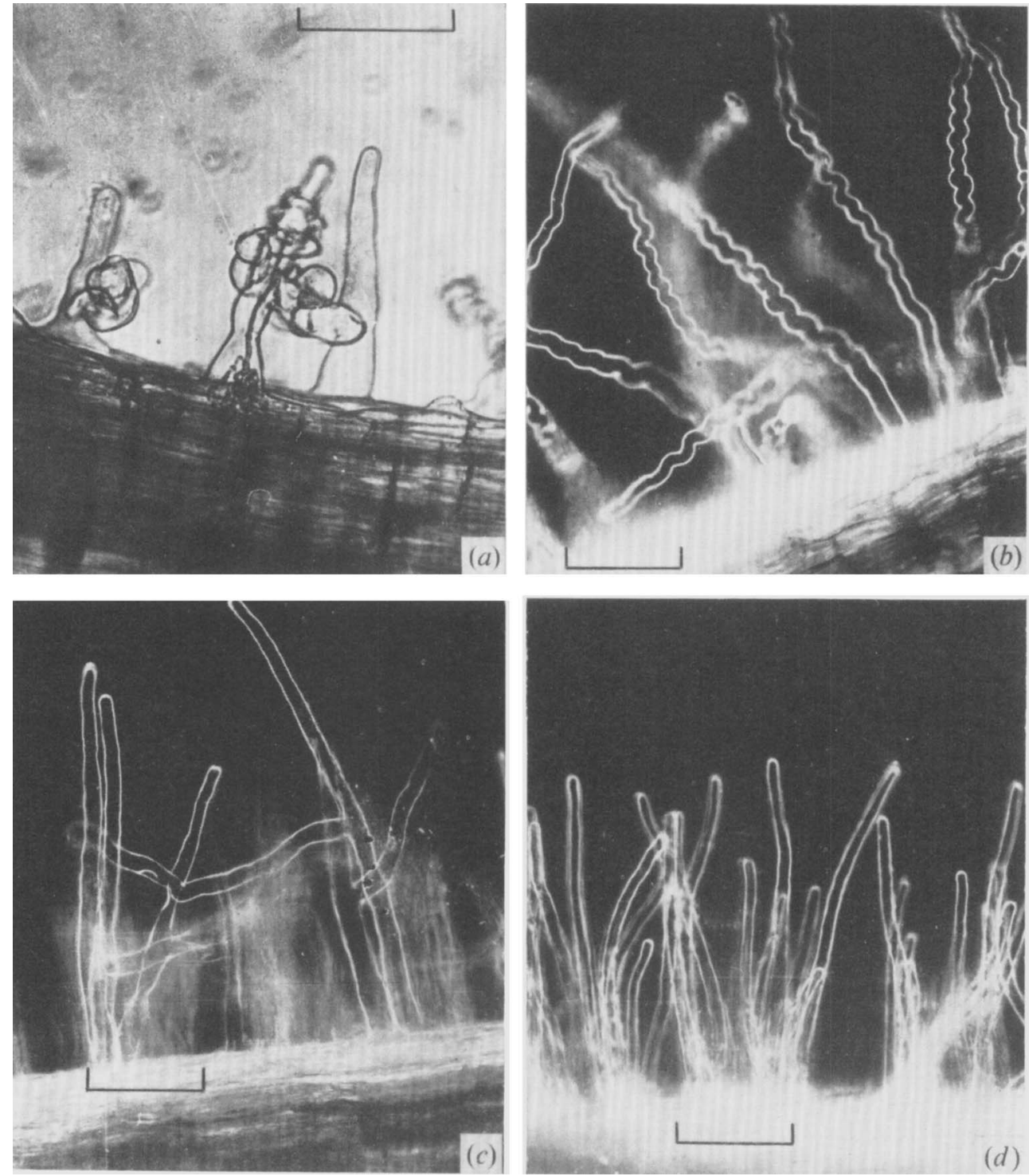

Fig. I. Deformation of root hairs of Trifolium repens. (a) Markedly curled; roots infected with Rhizobium trifolii. Note distinct points of bending, and the infection thread in one root hair. (b) Helical. (c) Branched. (d) Normal root hairs. Line indicates $50 \mu \mathrm{m}$.

modified by Nutman (1959), but without agar. The slides, each with two seedlings, were put into culture tubes containing $23 \mathrm{ml}$ nitrogen-free mineral solution (Fåhraeus, 1957). The plants grew in the light for I day before adding the solutions to be bioassayed. After 4 days the degree of deformation of root hairs was graded as follows: markedly curled, as in infected root hairs (Fig. I $a$ ); helical, Fig. I $b$; branched, as in Fig. I $(c)$. Fig. I $(d)$ shows root hairs of non-treated plants. On plants inoculated with this strain of Rhizobium the responses 'markedly curled' and 'helical' root hairs occurred at about equal frequencies. With the culture filtrate, or inoculated root medium, helical hairs were about six times more 
frequent than markedly curled. Both responses were, however, highly specific for Rhizobium trifolii strains which infected Trifolium repens. Markedly curled and helical are therefore recorded as one response. The number of root hairs in each category was counted under a microscope at $\times 100$ magnification. Only those root hairs seen clearly in the optical median plane on one side of the root were counted, with focusing adjustments made to keep this plane in view. Recordings were only made for root hairs formed after the plants were transferred to the growth slides.

Adsorption of deforming substances to roots of Trifolium repens and subsequent dissociation. Trifolium repens was grown axenically, in a stainless steel tank $(66 \times 46 \times 32 \mathrm{~cm})$ with a glass cover, on two finely meshed stainless steel grids $(33 \times 45 \mathrm{~cm})$ placed just above $\mathrm{I} 31$ mineral medium (Fåhraeus, 1957) continuously aerated with sterile air. The phosphate solution and the tank with the rest of the mineral medium were autoclaved separately for $\mathrm{I} h$ at $12 \mathrm{I}{ }^{\circ} \mathrm{C}$. Seeds ( $46 \mathrm{~g}$ ) were sterilized and spread on the grids. After germination for 2 days in the dark, the tank was placed in the light. After Io days the grids with the dense mat of plants with well-developed roots were transferred to trays $(45 \times 33 \times 3 \mathrm{~cm})$ where the roots were washed for $\mathrm{I} \mathrm{h}$ in 0.81 sterile mineral medium. Then the roots were placed in 0.61 of a culture filtrate of Rhizobium trifolii U226, which had been dialysed and then salts added to the same concentration as in the mineral medium (pH 6.3). After $45 \mathrm{~min}$ the roots were washed six times in 0.81 portions of mineral medium. Then the roots were 'eluted' for $45 \mathrm{~min}$ in a lightly shaken tray containing either $0.610 .2 \mathrm{~N}$-acetic acid or $0.616 \mathrm{M}$-urea. After dialysis against distilled water for $48 \mathrm{~h}$ at $4{ }^{\circ} \mathrm{C}$ and sterile filtration, these eluates were bioassayed for root-hair deforming substances.

Protein was determined by the method of Lowry, Rosebrough, Farr \& Randall (195I).

\section{RESULTS AND DISCUSSION}

The culture filtrate of Rhizobium trifolii grown in vitro (Table I A), and the root medium of Trifolium repens inoculated with $R$. trifolii (Table I B), produced two main fractions containing root-hair deforming substances on a MAK column. One fraction does not adsorb to MAK, the other does, but can be eluted by $0.8 \mathrm{~N}-\mathrm{NaCl}$. Nucleic acids attach by salt linkages to MAK in $0.4 \mathrm{~N}-\mathrm{NaCl}$ or lower concentration (Mandell \& Hershey, 1960). They can be eluted again unchanged by increasing the salt concentration. Each nucleic acid has its characteristic elution concentration of $\mathrm{NaCl}$. Only basic proteins attach to MAK, and they cannot be eluted again by $\mathrm{NaCl}$. According to the adsorption characteristics of MAK, the root-hair deforming substance in the non-adsorbing fraction is a protein, or a polysaccharide. It is difficult to separate them. The adsorbed fraction, eluted by $0.8 \mathrm{~N}-\mathrm{NaCl}$, is likely to be a nucleic acid, although no u.v. absorption was measured with a Shimadzu MPS-5oL recording spectrophotometer, even after concentration to the original volume fractionated.

Ribonuclease (Type I-A, Sigma), further purified according to Marmur (I96I), abolished the root-hair deforming ability of inoculated root medium. However, such experiments may be misleading if the enzyme preparation is not absolutely pure and when the substrate to be degraded by the enzyme is present in minute quantities. Removal of the active principle by adsorption to the added enzyme is also possible then.

$\mathrm{Ca}$-apatite has different adsorption characteristics to MAK, binding acidic proteins and nucleic acids by forces that can be broken by increasing the phosphate concentration. Complete elution of $\mathrm{Ca}$-apatite is obtained by pyrophosphate. Table 2 shows the root-hair deforming ability of inoculated medium separated into four fractions with Ca-apatite. The 
Table I. Deformation of root hairs of Trifolium repens $L$. $c v$. BETA by $(A)$ culture filtrate of Rhizobium trifolii $\mathrm{U} 226$ and $(B)$ root medium of T. repens $L$. $c v$. BETA inoculated with $R$. trifolii U226 fractionated on $M A K$.

Total for 16 plants.

\begin{tabular}{|c|c|c|c|}
\hline Fraction & $\begin{array}{l}\text { Markedly } \\
\text { curled and } \\
\text { helical }\end{array}$ & Branched & $\begin{array}{l}\text { Protein } \\
\text { content } \\
(\mu \mathrm{g} / \mathrm{ml})\end{array}$ \\
\hline (A) Not fractionated & 199 & 44 & 38 \\
\hline 1. Not adsorbed to MAK & 173 & I 2 & 92 \\
\hline 2. Eluted with $0.6 \mathrm{~N}-\mathrm{NaCl}$ & 77 & 55 & o \\
\hline 3. Eluted with $0.8 \mathrm{~N}-\mathrm{NaCl}$ & 154 & $2 \mathrm{I}$ & $<$ IO \\
\hline 4. Eluted with $\mathrm{I} \cdot 2 \mathrm{~N}-\mathrm{NaCl}$ & 25 & $4 \mathrm{I}$ & o \\
\hline Fraction $\mathrm{I}$, heated for $20 \mathrm{~min}$ at $85^{\circ} \mathrm{C}$ & 27 & 3 & - \\
\hline Fraction 3 , heated for $20 \mathrm{~min}$ at $85^{\circ} \mathrm{C}$ & 33 & 15 & - \\
\hline Not fractionated, heated for $20 \mathrm{~min}$ at $85^{\circ} \mathrm{C}$ & 35 & 15 & - \\
\hline Control (mineral medium only) & 27 & 23 & o \\
\hline Inoculated with $R$. trifolii $\mathrm{U} 226$ & I 339 & 129 & - \\
\hline (B) Not fractionated & 383 & 126 & 935 \\
\hline I. Not adsorbed to MAK & 339 & 136 & 785 \\
\hline 2. Eluted with $0.6 \mathrm{~N}-\mathrm{NaCl}$ & 56 & 30 & 0 \\
\hline 3. Eluted with $0.8 \mathrm{~N}-\mathrm{NaCl}$ & 150 & 172 & 0 \\
\hline 4. Eluted with $\mathrm{I} \cdot 2 \mathrm{~N}-\mathrm{NaCl}$ & 48 & 43 & o \\
\hline Fraction $\mathrm{I}$, heated for $20 \mathrm{~min}$ at $85^{\circ} \mathrm{C}$ & 708 & 319 & - \\
\hline Fraction 3 , heated for $20 \mathrm{~min}$ at $85^{\circ} \mathrm{C}$ & 310 & 52 & - \\
\hline Control (non-inoculated root medium) & 9 & 58 & 1420 \\
\hline Inoculated with $R$. trifolii $\mathrm{U} 226$ & 948 & 410 & - \\
\hline
\end{tabular}

Totals for 16 plants.

three fractions eluted by phosphate contain root-hair deforming substances, the pyrophosphate eluate does not. Since the Ca-apatite was washed three times between elution steps, this indicates that at least three compounds have deforming ability.

The adsorption experiments described in Table I suggest that the root-hair deforming substances in the culture filtrate of Rhizobium trifolii and in the inoculated root medium of Trifolium repens are chemically related. However, the substances must be different since the culture filtrate was inactivated completely after $20 \mathrm{~min}$ at $85^{\circ} \mathrm{C}$, whereas the inoculated root medium was not (Table 3 ). This difference in heat stability was also shown by Ljunggren (I969) and Yao \& Vincent (I969).

Table 3 shows that the deforming factors in the culture filtrate of Rhizobium trifolii became heat-stable when mixed with non-inoculated root medium of Trifolium repens. Thus, these factors are stabilized by attachment to a component formed by clover roots. Inoculated root medium is always more potent in its deforming ability than the Rhizobium culture filtrate.

High mol. wt compounds in the rhizosphere of axenic plants could be cell-wall components which are released gradually during growth. If the root component that binds, and heat-stabilizes, the root-hair deforming substances of Rhizobium also binds firmly to the host cell wall, it should be possible to purify the deforming substances by adsorption to roots and subsequent dissociation (as for purification of specific antibodies by adsorption to bacterial surfaces). Table 4 shows that root-hair deforming substances can be adsorbed to roots of Trifolium repens and 'eluted' again by dilute acetic acid or urea.

We have not shown that the root-hair deforming substances in the culture filtrate of 
Table 2. Deformation of root hairs of Trifolium repens $L$. $c v$. BETA when exposed to the root medium of $T$. repens inoculated with Rhizobium trifolii $\mathrm{U} 226$ after fractionation on Ca-apatite

Total for 16 plants.

Fraction

I. Not adsorbed to Ca-apatite

2. Eluted with $0.3 \mathrm{M}$-potassium phosphate

3. Eluted with $\mathrm{I} \cdot \mathrm{O} \mathrm{M}$-potassium phosphate

4. Eluted with saturated potassium phosphate

Control (mineral medium only)

Markedly
curled and
helical
1072
500
595
14
0

Protein

content

Branched $\quad(\mu \mathrm{g} / \mathrm{ml})$

$\begin{array}{rr}320 & 200 \\ 470 & 310 \\ 705 & 120 \\ 439 & 110 \\ 15 & 0\end{array}$

Table 3. Deformation of root hairs of Trifolium repens $L$. $c v$. BETA by culture filtrate of Rhizobium trifolii $\mathrm{U} 226$ and inoculated root medium of $T$. repens

Total for 16 plants.

\section{Solution bioassayed}

Culture filtrate

Culture filtrate. Heated to $85^{\circ} \mathrm{C}$ for $20 \mathrm{~min}$

Non-inoculated root medium

Inoculated root medium

Inoculated root medium. Heated to $85^{\circ} \mathrm{C}$ for $20 \mathrm{~min}$

A mixture of culture filtrate and non-inoculated root medium

A mixture of culture filtrate and non-inoculated root medium, heated to $85^{\circ} \mathrm{C}$ for $20 \mathrm{~min}$

Control. Mineral medium only

$\begin{array}{cc}\begin{array}{c}\text { Markedly } \\ \text { curled and } \\ \text { helical }\end{array} & \text { Branched } \\ 286 & 237 \\ 33 & 20 \\ 13 & 37 \\ 311 & 126 \\ 380 & 121 \\ 116 & 20 \\ 350 & 102 \\ 6 & 29\end{array}$

Table 4. Deformation of root hairs of Trifolium repens L. cr. BETA by culture filtrate of Rhizobium trifolii $\mathrm{U} 226$ and by eluates from roots pre-treated with this culture filtrate (see Methods)

Total for 16 plants.

\section{Fraction}

Culture filtrate $R$. trifolii $\mathbf{u} 226$

Culture filtrate added to roots and then 'eluted' with $0.2 \mathrm{~N}$-acetic acid

Culture filtrate added to roots and then 'eluted' with $6 \mathrm{M}$-urea

Untreated roots 'eluted' with $0.2 \mathrm{~N}$-acetic acid

Control. Mineral medium

$\begin{array}{cc}\begin{array}{c}\text { Markedly } \\ \text { curled and } \\ \text { helical }\end{array} & \text { Branched } \\ 267 & 96 \\ 269 & 8 \\ 139 & 39 \\ 46 & 12 \\ 37 & 4\end{array}$

Rhizobium trifolii also bind to the bacterial wall. If the substances are also components of the Rhizobium wall, they may react with the heat-stabilizing component in the clover root to establish a contact necessary for further penetration of Rhizobium into the root hair. This reaction may be a step in the 'recognition' of host and symbiont.

When root hairs are exposed to culture filtrate they become deformed at distinct points, possibly because the filtrate factors bind to specific receptor sites which contain the heatstabilizing host component. 
The authors are much indebted to Marit Steine for technical assistance and to Norges landbruksvitenskapelige forskningsråd (NLVF) for financial support. We thank Professor G. Fåhraeus and Dr H. Ljunggren at the Department of Microbiology, Agricultural College of Sweden for the Rhizobium strain.

\section{REFERENCES}

FÅHRAEUS, G. (1957). The infection of clover root hairs by nodule bacteria studied by a simple glass slide technique. Journal of General Microbiology 16, 374-38I.

GraHAM, P. H. (1963). Vitamin requirements of root nodule bacteria. Journal of General Microbiology 30 , 245-248.

Levin, $\varnothing,(1962)$. Column Chromatography of Protein: Calcium Phosphate. In Methods in Enzymology, vol. v. Edited by S. P. Colowick and N. O. Kaplan. New York and London: Academic Press.

LI, D. \& HuBBeLL, D. H. (1969). Infection thread formation as a basis of nodulation specificity on Rhizobiumstrawberry clover associations. Canadian Journal of Microbiology 15, I1 33-11 36.

LJUNGGREN, H. (1969). Mechanism and pattern of Rhizobium invasion into leguminous root hairs. Physiologia plantarum, Supplementum v.

Lowry, O. H., Rosebrough, N. J., Farr, A. L. \& Randall, R. J. (1951). Protein measurement with the Folin phenol reagent. Journal of Biological Chemistry 193, 265-275.

Mandell, J. D. \& Hershey, A. D. (1969). A fractionating column for analysis of nucleic acids. Analytical Biochemistry I, 66-77.

MARMUR, J. (196I). A procedure for the isolation of deoxyribonucleic acid from microorganisms. Journal of Molecular Biology 3, 208-218.

Nutman, P. S. (1959). Some observations on root-hair infection by nodule bacteria. Journal of Experimental Botany 10, 250-263.

Sahlman, K. \& F̊nRaeus, G. (1963). An electron microscope study of root-hair infection by Rhizobium. Journal of General Microbiology 33, 425-427.

Solmeim, B. \& RAA, J. (1971). Evidence countering the theory of specific induction of pectin degrading enzymes as basis for specificity in Rhizobium-Leguminosae associations. Plant and Soil 35, 275-280.

YAO, P. Y. \& VinCENT, J. M. (1969). Host specificity in the root hair 'Curling Factor' of Rhizobium spp. Australian Journal of Biological Science 22, 413-423. 